\title{
THE SPANWISE VARIATION OF ROOF-LEVEL TURBULENCE IN A STREET CANYON FLOW
}

\author{
Tomek Jaroslawski \& Eric Savory \\ Department of Mechanical \& Materials Engineering \\ The University of Western Ontario \\ London, Canada \\ tjarosla@uwo.ca
}

\author{
Laurent Perret \& Karin Blackman \\ LHEEA UMR 6598 CNRS \\ Ecole Centrale de Nantes \\ Nantes, France
}

\begin{abstract}
The effect of upstream roughness on turbulent street canyon flow is presented. Horizontal measurements were conducted at near roof level of a street canyon using particle image velocimetry in a wind tunnel. Three upstream roughness arrays and two canyon width to height aspect ratios (W/ h $=1$ and 3) were investigated. The arrays consisted of 3D cubes (plan area density, $\lambda_{\mathrm{p}}=25 \%$ ), $1 \mathrm{~h}$ spaced $2 \mathrm{D}$ bars (skimming flow, $\lambda_{\mathrm{p}}=50 \%$ ) and $3 \mathrm{~h}$ spaced $2 \mathrm{D}$ bars (wake interference flow, $\lambda_{\mathrm{p}}=25 \%$ ). Two-point correlations and integral length scales are computed over the different configurations. The results show a significant effect of upstream roughness on these quantities. It was found that a $3 \mathrm{D}$ upstream roughness has a significantly weaker correlation in the spanwise direction. A similar trend is observed in spanwise integral length scales. The shear layer boundary was found to be related to the strength of the correlations near roof level of the street canyon.
\end{abstract}

Keywords: Boundary layer - Street canyon - Particle Image Velocimetry • Wind tunnel

\section{INTRODUCTION}

Air quality in urban environments is a critical issue in present times with the resulting socioeconomic implications being of great concern. Pollution in the earth's atmosphere leads to human death, disease and harm to our natural resources [1]. The simple street canyon model is a useful representation of most urban street configurations. The effects of canyon aspect ratio AR (streamwise width $\mathrm{W} /$ canyon height $\mathrm{h}$ ) and upstream roughness on street canyon flow is well studied. Grimmond and Oke [2] defined three regimes of flow in urban environments; skimming flow, wake interference flow and isolated roughness flow. They also found that the plan area packing density $\left(\lambda_{\mathrm{p}}\right)$ of the upstream roughness and whether it was $2 \mathrm{D}$ or $3 \mathrm{D}$ had an impact on the flow within the canyon. Experimental wind tunnel studies on street canyons frequently use Particle Image Velocity (PIV) to measure the flow field, and mostly conduct measurements in a single vertical plane, such as Salizzoni Marro, Soulhac, Grosjean \& Perkins [3], Savory, Perret \& Rivet [4] and Blackman, Perret \& Savory [5]. When studying this configuration in a wind tunnel, Savory, Perret \& Rivet [4] noted that it is crucial to match the roughness length scale $\left(z_{0}\right)$ and the integral length scale $\left(\mathrm{L}_{\mathrm{uu}}\right)$ within factors of 2-3 to ensure that full and model scale are matched properly. It was also noted that the geometry of the upstream roughness significantly effects the structure of the oncoming boundary layer, where $3 \mathrm{D}$ roughness is found to generate $3 \mathrm{D}$ turbulent structures which resembles a more realistic boundary layer found in nature. Suggestions by Savory, Perret \& Rivet [4] have been employed in the present work.

Turbulence is a 3D phenomenon and thus to understand turbulent street canyon flow properly one must investigate how the flow behaves in both the spanwise (y) direction and the vertical (z) direction. Shaw, Brunet, Finnigan \& Raupach [6] conducted a wind tunnel study of air flow over waving wheat. Two-point, space-time correlations of streamwise (x) and vertical velocity components were computed from the wind tunnel simulation of an atmospheric boundary layer, with the wheat canopy model constructed of flexible nylon stalks. It was concluded that it was not appropriate to apply Taylor's hypothesis of frozen turbulence in the region of the canopy and, therefore, the integral length scales were computed directly from two-point statistics. It was also found that the lateral integral length scales were smaller than those computed in the streamwise direction by factors ranging from 1.9 to 4.2 . Raupach, Finnigan \& Brunet [7] stated that the approach of applying the Taylor's hypothesis is fraught with difficulty as high turbulence intensities ( $\left.u^{\prime} / \bar{U}>1\right)$ are present within the canopy. Inagaki, Kanda, Sato \& Michioka [8] conducted multipoint measurements (3D velocities and temperatures) in a cubical array using multiple sonic anemometers aligned at equal heights in the streamwise and spanwise directions. Using twopoint correlations, they reported that the correlation of the fluctuating streamwise velocity, the difference between instantaneous and mean velocities $\left(u^{\prime}=u-\bar{U}\right)$ was higher along the streamwise direction than for an equal magnitude of spanwise separation. The result was attributed to the existence of coherent structures elongated along the streamwise direction. It was postulated that the coherent structure of $\mathrm{u}^{\prime}$ is geometrically similar irrespective of the type of roughness. 
Raupach, Finnigan \& Brunet [7] conducted two-point correlations of various model and field canopies in the $\mathrm{x}-\mathrm{Z}$ and $\mathrm{y}-\mathrm{z}$ planes. In the $\mathrm{x}-\mathrm{z}$ plane the streamwise fluctuating velocity correlation produced nearly elliptical stretched correlation contours, with a tilt angle of approximately 18 degrees, an effect that was reported to diminish within the canopy. Shaw, Brunet, Finnigan \& Raupach [6] suggest that this more rapid reduction of correlation within the canopy is due to the creation of small scale motion and the breakdown of large scale flow by canopy elements. In contrast, the correlation of the vertical fluctuating velocity revealed nearly circular correlation contours and was found to decay much more rapidly with spatial separation. The correlations in the $y-z$ plane produced contours which were nearly circular for both streamwise and vertical fluctuating velocities. Raupach, Finnigan \& Brunet [7] concluded that in a time-averaged sense, fluid motions near the top of the canopy are well correlated over length scales of the order of $h$. It is also suggested that zones where the sign of the correlation reverses could be a direct consequence of the formation of dominant flow structures [6]. The effect of the roughness and canyon geometry on the mean turbulent statistics near roof level in the horizontal plane is investigated in this work. The questions to be addressed in the present paper are:

- What is the impact of $2 \mathrm{D}$ versus $3 \mathrm{D}$ arrays and $\lambda_{p}$ on two-point correlations and integral length scales in the streamwise and spanwise direction in a horizontal plane near roof-level of the canyon?

- What does this tell us about the mean structure of the flow at this location of the street canyon?

The objective of this present research is to establish how the oncoming boundary layer flow interacts with the street canyon over a range of configurations. The flow will be characterized in the spanwise direction to complement the work of Blackman, Perret \& Savory [5], who characterized the vertical plane. The correlations and scales of turbulence will also be investigated to further understand the dynamics of the flow and structure of turbulence in the spanwise direction. The present results provide a clearer picture on the nature of $3 \mathrm{D}$ turbulent flow in street canyons.

\section{EXPERIMENTAL SETUP}

The experiments were conducted in the low-speed, suckdown boundary layer wind tunnel in the LHEEA Laboratory (École Centrale Nantes, France). The dimensions of the working section were $2 \mathrm{~m}$ (width) $\times 2 \mathrm{~m}$ (height) $\times 24 \mathrm{~m}$ (length) and the wind tunnel had a 5:1 ratio inlet contraction. Boundary layer development was initiated by five $800 \mathrm{~mm}$ high vertical tapered spires located immediately downstream of the contraction and a $200 \mathrm{~mm}$ high solid fence across the working section positioned $750 \mathrm{~mm}$ downstream of the spires. The street canyon flow measurements were taken $5.5 \mathrm{~m}$ downstream of this initial development region. Two canyon aspect ratios were studied for three upstream roughness conditions. The street canyon was constructed using two square cross section rectangular bars with a height of $50 \mathrm{~mm}(\mathrm{~h})$ and a lateral length of $1500 \mathrm{~mm}$. The upstream roughness conditions consisted of a staggered cubical array $\left(\lambda_{\mathrm{p}}=25 \%\right)$ or $2 \mathrm{D}$ square cross section rectangular bars with a spacing of $1 \mathrm{~h}$ or $3 \mathrm{~h}\left(\lambda_{\mathrm{p}}=25 \%\right.$ and $\lambda_{\mathrm{p}}=$ $50 \%$ ). The height of the cubes and 2D bars was $50 \mathrm{~mm}$. It should be noted that the experimental conditions in this present work are the same as in Blackman, Perret \& Savory [5]. A schematic of the experimental setup can be found in figure 1 .

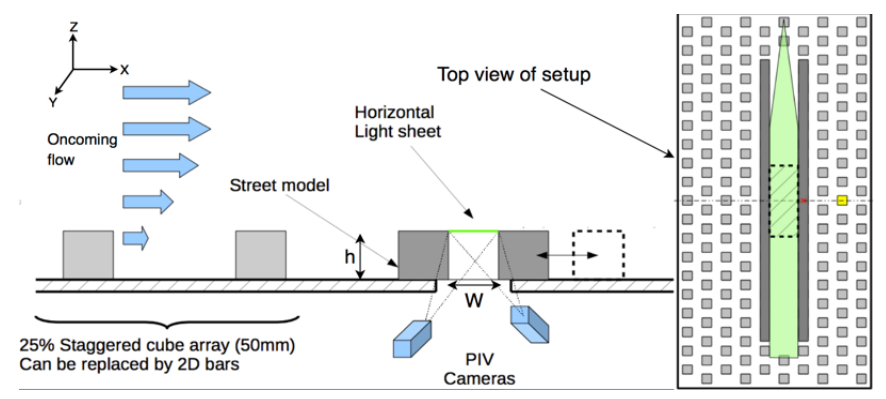

Figure 1. Experimental Setup

Stereoscopic PIV measurements were conducted in the horizontal plane located at a height of $0.9+/-0.05 \mathrm{~h}$ and aligned with the free stream flow. This height was verified by comparing turbulent statistics to those from Blackman, Perret \& Savory [5] which consisted of measurements in the vertical plane. The PIV setup was located beneath the wind tunnel floor and images were taken through a glass floor. The final spatial resolution of the vector field was $1.6 \mathrm{~mm}(0.032 \mathrm{~h})$ and a temporal sampling frequency of $7 \mathrm{~Hz}$ was used. The fields of view were $1 \mathrm{~h} \times 6 \mathrm{~h}$ and $3 \mathrm{~h} \times 6 \mathrm{~h}$ for the $1 \mathrm{~h}$ and $3 \mathrm{~h}$ canyons, respectively. A Litron double cavity $2 \times 200 \mathrm{~mJ} \mathrm{Nd}$-Yag laser was used to illuminate the measurement region. The flow was seeded with glycol/water droplets (average diameter of $1 \mu \mathrm{m}$ ) via a fog generator. An iterative cross-correlation analysis was performed which consisted of an initial window size of 64 x 64 pixels with a final interrogation of $32 \times 32$ pixels and the overlap of the analysis window was $50 \%$. A pulse interval of $500 \mu$ s was used in the computation of the velocity vector fields. A pitot-static tube located at $\mathrm{x}=15 \mathrm{~m}, \mathrm{y}=0 \mathrm{~m}, \mathrm{z}=1.5 \mathrm{~m}$ was used to measure dynamic pressure from which the velocity was determined to be $5.9 \mathrm{~m} / \mathrm{s}$. This velocity was used for all of the experiments in this present work giving a Reynolds number of $1.9 \times 10^{4}$, based on this velocity, $\mathrm{U}_{\mathrm{e}}$ and canyon height, $\mathrm{h}$.

\section{RESUlTS AND DiscuSSION}

In this section, two-point statistics are discussed in part (a) and computed integral length scales are assessed in (b).

\section{a) Two-Point Statistics}

Two-point space and time fluctuating velocity correlations offer important information regarding the nature of the flow field which single point measurements cannot provide. A two-point spatial correlation was conducted using the middle of the street canyon $\left(\mathrm{x}_{\mathrm{ref}}=0 \mathrm{~h}, \mathrm{y}_{\mathrm{ref}}=0 \mathrm{~h}\right)$ as the reference point. The two-point correlation coefficient was computed using (1).

$$
R_{\mathrm{uu}}\left(\mathrm{x}_{\mathrm{ref}}, \mathrm{y}_{\mathrm{ref}}, \mathrm{x}, \mathrm{y}\right)=\frac{\overline{\mathrm{u}^{\prime}\left(\mathrm{x}_{\mathrm{ref}}, \mathrm{y}_{\text {ref }}\right) \mathrm{u}^{\prime}(\mathrm{x}, \mathrm{y})}}{\sqrt{\frac{\mathrm{u}^{\prime 2}\left(\mathrm{x}_{\mathrm{ref}}, \mathrm{y}_{\mathrm{ref}}\right)}{\sqrt{\mathrm{u}^{\prime 2}(\mathrm{x}, \mathrm{y})}}}} .
$$


Contours of the correlation fields are presented in figure 2 and figure 3 for $1 \mathrm{~h}$ and $3 \mathrm{~h}$ canyon widths, respectively. Plots of the correlations along the $\mathrm{x}$ and $\mathrm{y}$ centrelines for streamwise $\left(\mathrm{u}^{\prime}\right)$ and vertical $\left(\mathrm{w}^{\prime}\right)$ fluctuating velocities ( $w$ ith $\mathrm{x}_{\mathrm{ref}}=0 \mathrm{~h}, \mathrm{y}_{\mathrm{ref}}=0 \mathrm{~h}$ set as the reference point) can be found in figure 4 to figure 5 . It can be observed that the correlation is symmetrical for all quantities in the spanwise direction. Symmetry in the y-z plane for correlations of streamwise and vertical velocity fluctuations was also observed by Shaw, Brunet, Finnigan \& Raupach [6] and Raupach, Finnigan \& Brunet [7]. Raupach, Finnigan \& Brunet [7] noted that the correlation contours were roughly spherical with a radius of $0.8 \mathrm{~h}$. Within figure 2 and figure 3 , the effect of roughness on the flow can be seen qualitatively. The effect of roughness is more prominent in $\mathrm{C} 1 \mathrm{~h}$ than $\mathrm{C} 3 \mathrm{~h}$ configurations. The structure of the correlation is more elongated in the streamwise direction and is narrower for $\mathrm{C} 3 \mathrm{~h}$. The opposite is true for $\mathrm{C} 1 \mathrm{~h}$, with the structure of the correlation elongated in the spanwise direction. For the $\mathrm{AR}=1$ canyons the largest spherical radius of the correlation (region of the correlation field which is circular) was $0.3 \mathrm{~h}$ for the $\mathrm{C} 1 \mathrm{hR} 3 \mathrm{~h}$ configuration, whilst for $\mathrm{AR}=3$ the largest radius was found to be approximately $0.3 \mathrm{~h}$ for $\mathrm{C} 3 \mathrm{hR} 3 \mathrm{~h}$. This suggests that the size of the spherical radius of the correlations is independent of canyon geometry, and only dependent on roughness (other configurations had smaller spherical correlation radii, all within $0.1 \mathrm{~h}-0.2 \mathrm{~h}$ for both $\mathrm{R} 1 \mathrm{~h}$ and $\mathrm{Rcu}$ ). Although the spherical correlation radii are smaller than those found by Raupach, Finnigan \& Brunet [7], this could be attributed to the different flow regimes (flow over a model wheat field) and the measurement region being higher $(\mathrm{z}=1 \mathrm{~h}$ versus $0.9 \mathrm{~h}$ in the present work).
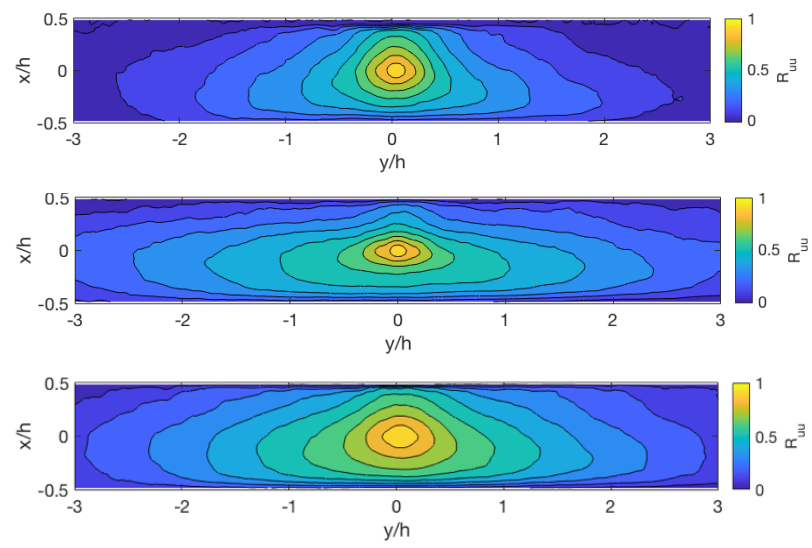

Figure 2. Two-point correlations: (top) $\mathrm{C} 1 \mathrm{hRcu}$ (middle) $\mathrm{C} 1 \mathrm{hR} 1 \mathrm{~h}$ and (bottom) C1hR3h

Raupach, Finnigan \& Brunet [7] defined a significant correlation to be $\mathrm{R}_{\mathrm{uu}}>0.2$ at height $\mathrm{h}$. Referring to figures 4 and 5 it can be found that that for the C1hR $1 \mathrm{~h}$ and $\mathrm{C} 1 \mathrm{hR} 3 \mathrm{~h}$ configurations there is a significant correlation for the entire spanwise width of the canyon ( $-3 \mathrm{~h}$ to $3 \mathrm{~h})$. The $\mathrm{C} 1 \mathrm{hRcu}$ configuration shows a significant spanwise correlation from $1.5 \mathrm{~h}$ to $1.5 \mathrm{~h}$. It is also observed that $\lambda_{\mathrm{p}}$ does not seem to effect the spanwise correlation for the $\mathrm{Clh}$ configurations. For the $\mathrm{C} 3 \mathrm{~h}$ configurations the effect of roughness on the correlations
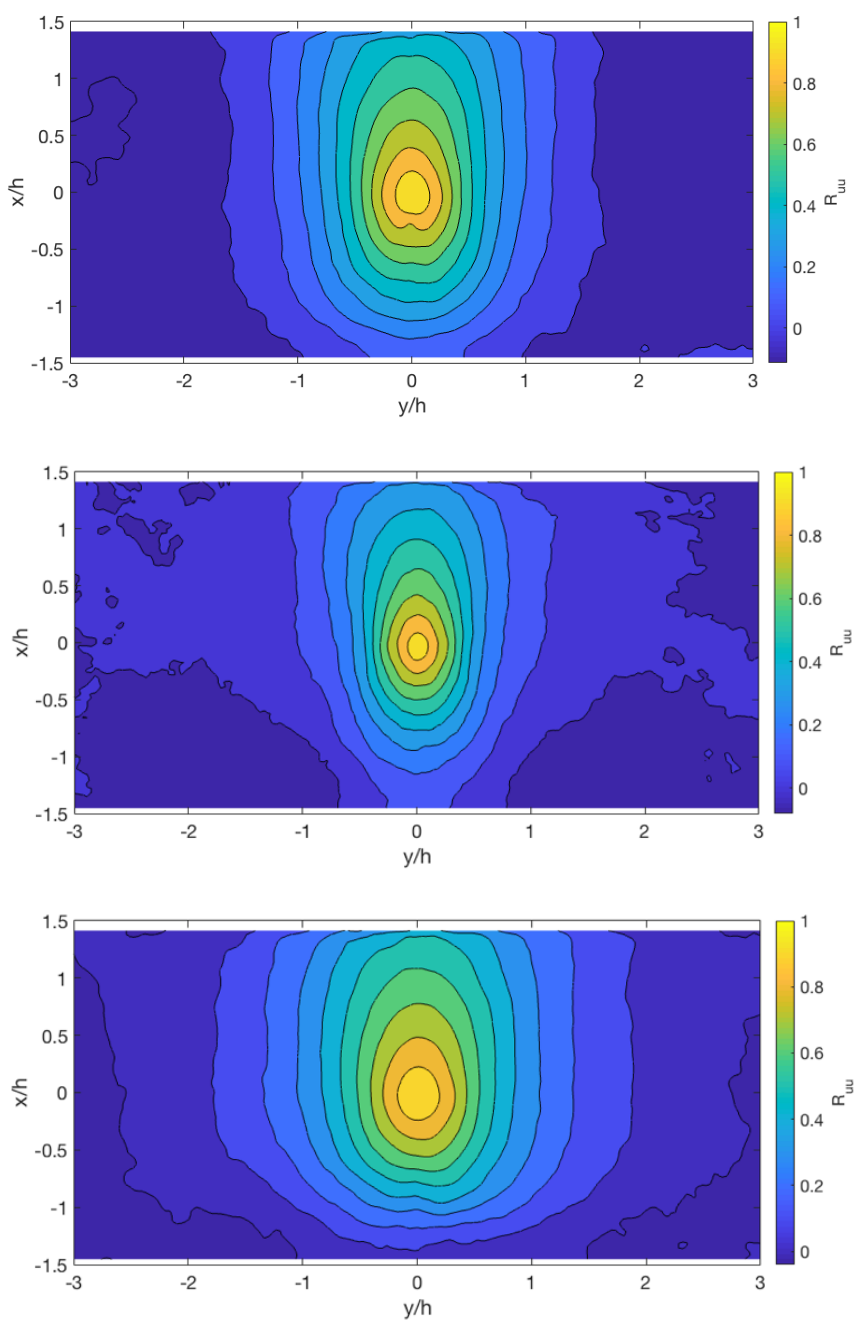

Figure 3. Two-point correlations: (top) $\mathrm{C} 3 \mathrm{hRcu}$ (middle) $\mathrm{C} 3 \mathrm{hR} 1 \mathrm{~h}$ and (bottom) C3hR3h

is less strong. The $\mathrm{C} 3 \mathrm{hR} 3 \mathrm{~h}$ configuration has a significant spanwise correlation from $-1.5 \mathrm{~h}$ to $1.5 \mathrm{~h}, \mathrm{C} 3 \mathrm{hR} 1 \mathrm{~h}$ and $\mathrm{C} 3 \mathrm{hRcu}$ are $-1 \mathrm{~h}$ to $1 \mathrm{~h}$ and $-0.8 \mathrm{~h}$ to $0.8 \mathrm{~h}$, respectively. It can be concluded that spanwise correlations decay much more rapidly when AR is increased. The smallest correlation for $\mathrm{C} 1 \mathrm{~h}$ was the largest for $\mathrm{C} 3 \mathrm{~h}$. An opposite trend is observed for correlations in the streamwise direction, with $\mathrm{C} 3 \mathrm{~h}$ configurations having a significant correlation for most the canyon width (-1h to $1.5 \mathrm{~h})$ and the $\mathrm{C} 1 \mathrm{~h}$ configurations having significant correlations from approximately $-0.4 \mathrm{~h}$ to $0.4 \mathrm{~h}$. The correlation could decay more rapidly for $\mathrm{C} 1 \mathrm{~h}$ than $\mathrm{C} 3 \mathrm{~h}$ because of a larger circulation region expected in a larger AR canyon. It is also quite possible that the shear layer has an impact on the correlation decay. Blackman, Perret \& Savory [5] computed the shear layer boundaries from vertical PIV data for the same configurations present in this work. The shear layer boundary was computed using turbulent kinetic energy in the shear layer [5]. They found that C3h had thicker shear layers than $\mathrm{C} 1 \mathrm{~h}$. A thicker and larger shear layer would oscillate at a lower frequency, resulting in the flow in the canyon to have a lower frequency as well, this would result in a stronger correlation near roof level of the canyon with the AR 
$=3$. On the contrary, $\mathrm{C} 1 \mathrm{~h}$ was found to have a smaller shear layer [5]. The faster moving and thinner shear layer would cause the correlation near-roof level to decay more rapidly. In the present work, the streamwise correlation at near-roof level for $\mathrm{C} 1 \mathrm{~h}$ was symmetrical but asymmetrical for $\mathrm{C} 3 \mathrm{~h}$ (see figures 4 and 5). This, again, can be explained by the shear layer boundaries computed by Blackman, Perret \& Savory [5]. Blackman, Perret \& Savory [5] found shear layer boundaries to be less symmetrical in the streamwise direction for $\mathrm{C} 3 \mathrm{~h}$ than $\mathrm{C} 1 \mathrm{~h}$. For $\mathrm{C} 3 \mathrm{~h}$ the thickness of the shear layer boundary was much thicker at the downstream wall than near the upstream wall (approximately 4x larger), this difference being significantly smaller for $\mathrm{C} 1 \mathrm{~h}$ (approximately $2 \mathrm{x}$ larger). There appears to be a relationship between streamwise correlation symmetry at roof level and the geometry of the shear layer. Finally, it was stated above that the effect of roughness is much more profound on the spanwise correlations near the roof level for canyons with an $\mathrm{AR}=1$ than 3 . This trend is, again, present in the shear layer boundaries computed by Blackman, Perret \& Savory [5], with the $\mathrm{C} 1 \mathrm{~h}$ configurations varying more with roughness. Correlation decay in the streamwise direction was found to be related to shear layer boundaries in that those configurations with the thickest shear layer had the strongest correlations at roof level.
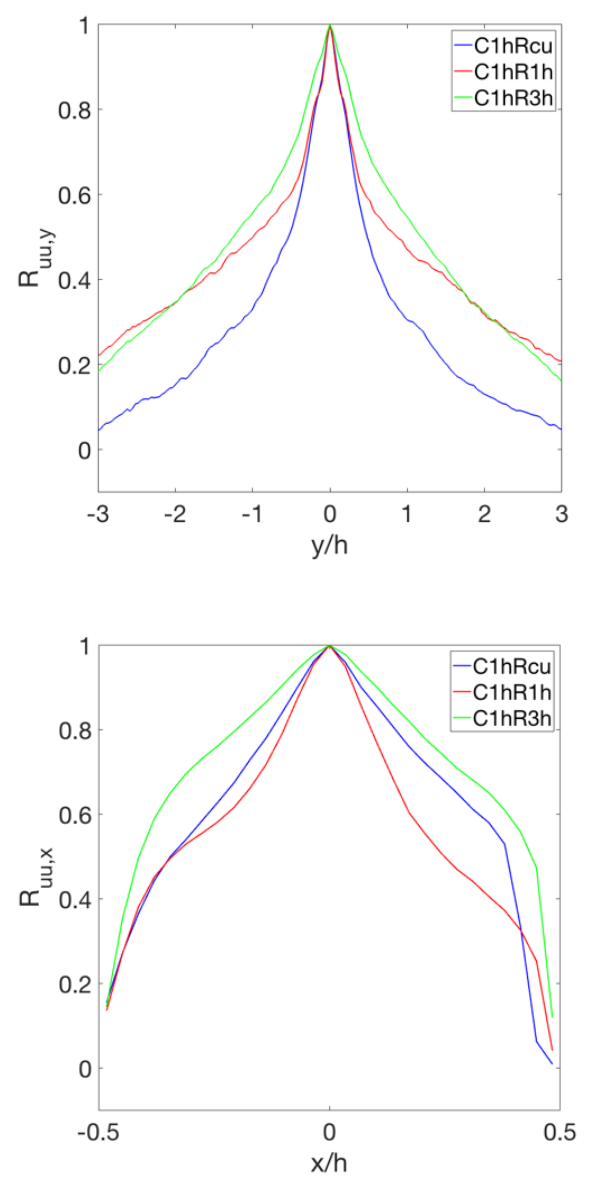

Figure 4. $\mathrm{R}_{\mathrm{uu}}$ two-point corelations for $\mathrm{C} 1 \mathrm{~h}$ (top: $\mathrm{y}$-direction, bottom: $\mathrm{x}-$ direction)
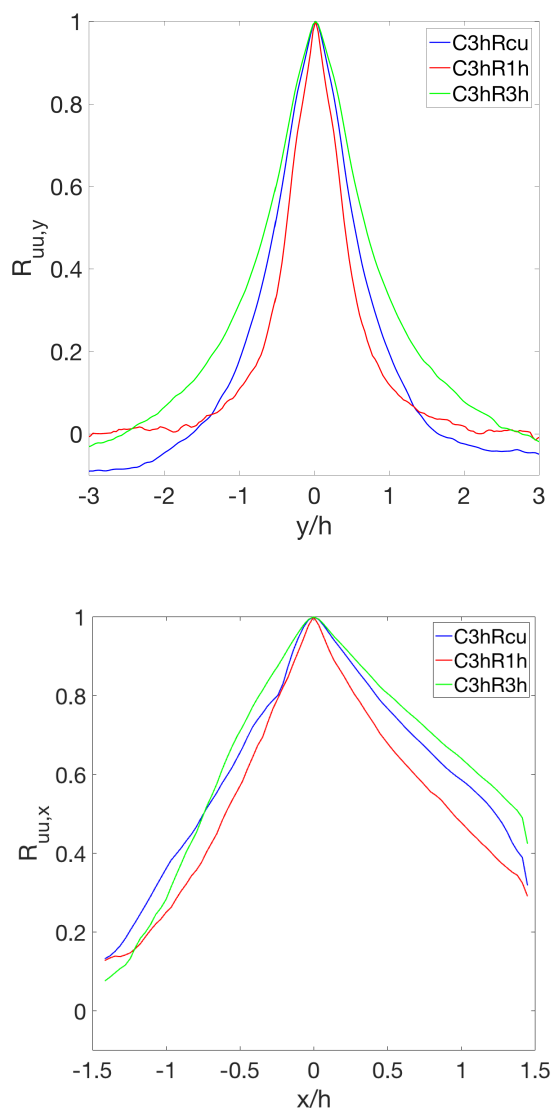

Figure 5. $\mathrm{R}_{\mathrm{uи}}$ two-point corelations for C3h (top: $\mathrm{y}$-direction, bottom: $\mathrm{x}-$ direction)

\section{b) Integral Length Scale $\left(L_{u u}\right)$}

The turbulence integral length scale can be defined as the size of the average-energy containing eddy. The turbulence integral length scales were calculated using (2) for the spanwise velocity fluctuations and (3) for the streamwise velocity fluctuations. The reference points used to compute $\mathrm{R}_{\mathrm{uu}}$ used in (2) and (3) were $x_{\text {ref }}=-0.5 h, y_{\text {ref }}=0 h$ for the streamwise $L_{u u}$ and $\mathrm{x}_{\text {ref }}=0 \mathrm{~h}, \mathrm{y}_{\mathrm{ref}}=-3 \mathrm{~h}$ for the spanwise $\mathrm{L}_{\mathrm{uu}}$. The integral length scale was computed by integrating until the first zero crossing of a two-point spatial correlation.

$$
\begin{aligned}
& \mathrm{L}_{\mathrm{uu}}(\mathrm{y})=\int\left(\mathrm{R}_{\mathrm{uu}}\right) d y \\
& \mathrm{~L}_{\mathrm{uu}}(\mathrm{x})=\int\left(\mathrm{R}_{\mathrm{uu}}\right) \mathrm{dx}
\end{aligned}
$$

The integral length scales for both the streamwise fluctuating velocity $\left(u^{\prime}\right)$ and vertical fluctuating velocity $\left(w^{\prime}\right)$ in the $x$ and $\mathrm{y}$ directions are presented in figure 6 . It may be seen that roughness and $A R$ have a significant effect on the spanwise integral length scale. $\mathrm{L}_{\mathrm{uu}, \mathrm{y}}$ for $\mathrm{C} 1 \mathrm{hRcu}$ was found to be almost $50 \%$ smaller than the $\mathrm{L}_{\text {uu,y }}$ for $\mathrm{C} 1 \mathrm{hR} 1 \mathrm{~h}$ and $\mathrm{C} 1 \mathrm{hR} 3 \mathrm{~h}$. This suggests whether the flow is $2 \mathrm{D}$ or $3 \mathrm{D}$ influences the magnitude of $\mathrm{L}_{\mathrm{uu}, \mathrm{y}}$ not $\lambda_{\mathrm{p}}$. Blackman, Perret \& Savory [5] found that the 
streamwise integral length scale was larger for the 2D case than the $3 \mathrm{D}$ case when packing density was equal. Volino, Schultz \& Flack [9] also observed that integral length scales where significantly smaller for 3D than for 2D cases. The results from Takimoto, Ignaki, Kanda, Sando \& Michioka [10] contradict this as they showed larger $\mathrm{L}_{\mathrm{uu}}$ in the $3 \mathrm{D}$ configuration. However, as suggested by Blackman, Perret \& Savory [5] this could be due the simulation method employed, as no spires were used in the experiment, resulting in a smaller boundary layer. Blackman, Perret \& Savory [5] found that, at roof-level, the streamwise $\mathrm{L}_{\mathrm{uu}}$ for Rcu was approximately $4 \mathrm{~h}$ but it is lower in the present work because the measurements were taken at $\mathrm{z} / \mathrm{h}=$ 0.9 . The present results show that that $\mathrm{L}_{\mathrm{uu}}$ is smaller for $3 \mathrm{D}$ than 2D flows in the spanwise direction, which was also found in previous work ([5] and [9]) for the streamwise direction. The integral length scales for vertical velocity fluctuations $\left(\mathrm{L}_{\mathrm{ww}}\right)$ were found to be approximately 3-4 times smaller than $\mathrm{L}_{\mathrm{uu}}$.
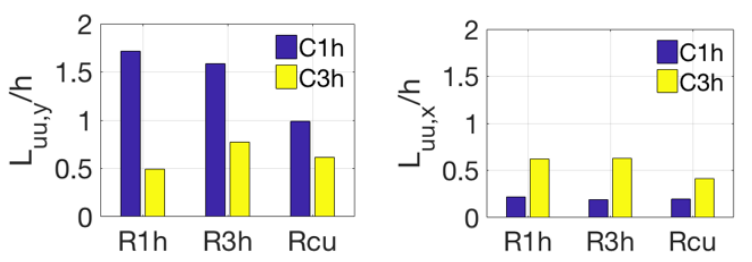

Upstream Roughness
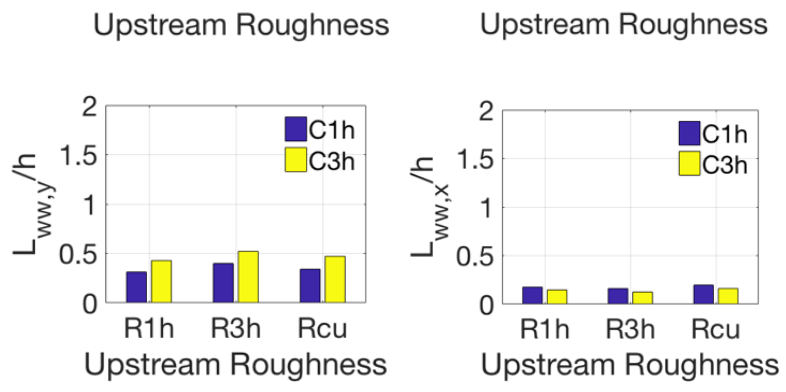

Figure 6. Impact of roughness on $\mathrm{L}_{\mathrm{uu}, \mathrm{y}}, \mathrm{L}_{\mathrm{uu}, \mathrm{x}}$ (top) and $\mathrm{L}_{\mathrm{ww}, \mathrm{y}}, \mathrm{L}_{\mathrm{ww}, \mathrm{x}}$ (bottom)

\section{CONCLUSION}

Horizontal measurements were conducted at near roof-level in a street canyon using particle image velocimetry in a wind tunnel, for 6 configurations of upstream roughness and canyon aspect ratio. It was observed that the two-point correlations were symmetrical for all quantities in the spanwise direction. Stronger correlations were found for 2D roughness arrays than in $3 \mathrm{D}$ arrays and the planform packing density was found to have no effect on spanwise correlations. It was found that the correlation decay in the streamwise direction was related to shear layer boundaries such that the configurations with the thickest shear layer had the strongest correlation. The $\mathrm{L}_{u u}$ was found to be smaller for $3 \mathrm{D}$ than $2 \mathrm{D}$ flows in the spanwise direction.

\section{ACKNOWLEDGMENT}

The authors would like to thank Mr Thibaut Piquet for his technical support during the experimental program and the LHEEA research group.

\section{REFERENCES}

[1] World Health Organization (2014) 7 million premature deaths annually linkedtoairpollution.http://www.who.int/mediacentre/news/releases/2014 /air-pollution/en/J.

[2] Grimmond CSB, Oke TR (1999) Aerodynamic properties of urban areas derived from analysis of surface form. J Appl Meteorol 38:1262-1292

[3] Salizzoni, P., Marro, M., Soulhac, L., Grosjean, N., \& Perkins, R. J. (2011). Turbulent transfer between street canyons and the overlying atmospheric boundary layer. Boundary-Layer Meteorology, 141(3), 393414.

[4] Savory, E., Perret, L., \& Rivet, C. (2013). Modelling considerations for examining the mean and unsteady flow in a simple urban-type street canyon. Meteorology and Atmospheric Physics, 121(1-2), 1-16.

[5] Blackman, K., Perret, L., \& Savory, E. (2015a). Effect of upstream flow regime on street canyon flow mean turbulence statistics. Environmental Fluid Mechanics, 15, 823-849.

[6] Shaw. R.H, Brunet.Y, Finnigan J.J \&Raupach M.R (1995). A wind tunnel study of air flow in waving wheat: two-point velocity statistics. BoundaryLayer Meteorology, 76, 349-376.

[7] Raupach, M. R., Finnigan, J. J., \& Brunet, Y. (1996). Coherent eddies and turbulence in vegetation canopies: the mixing-layer analogy. BoundaryLayer Meteorology, 78, 351-382.

[8] Inagaki, A., Maruyama, A., \& Kanda, M. (2009). Spatial and temporal scales of coherent turbulence over outdoor reduced urban scale model, July 2009 [The Seventh International Conference on Urban Climate, Yokohama, Japan].

[9] Volino, R. J., Schultz, M. P., \& Flack, K. A. (2009). Turbulence structure in a boundary layer with two-dimensional roughness. Journal of Fluid Mechanics, 635, 75-101.

[10] Takimoto, H., Inagaki, A., Kanda, M., Sato, A., \& Michioka, T. (2013). Length-Scale Similarity of Turbulent Organized Structures over Surfaces with Different Roughness Types. Boundary-Layer Meteorology, 147(2), 217-236. 